\title{
ERRATUM
}

K. D. Kim - G. Z. Liu - S. C. Han

\section{A resultant 8-node solid-shell element for geometrically nonlinear analysis}

Published online: 27 December 2004

(c) Springer-Verlag 2004

Due to an unfortunate error, the original Fig. 13 was replaced by Fig. 14 when the proof corrections were carried out. We apologise for this mistake. The correct Figure 13 is shown below:

Fig. 13 Square clamped Plate subjected to uniform pressure

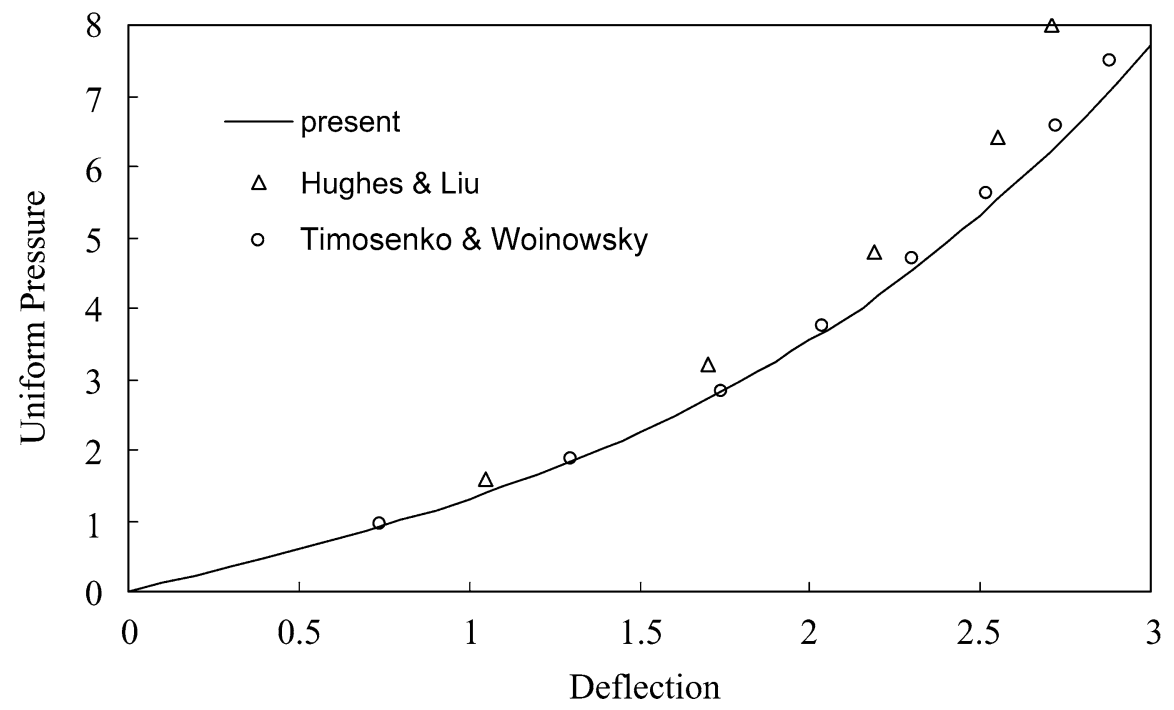

The online version of the original article can be found at http://dx.doi.org/10.1007/s00466-004-0606-9

K. D. Kim $(\bowtie) \cdot$ G. Z. Liu

School of Civil Engineering,

Asian Institute of Technology, P.O.Box 4,

Klongluang, Pathumthani, 12120, Thailand.

S. C. Han

Department of Civil Engineering,

Daewon Science College, Jecheon, Chung-buk,

390-702, Korea 